\title{
CONTAMINAÇÃO POR METAIS NA CARNE E EM ESTRUTURAS COMESTÍVEIS DO CARANGUEJO-UÇÁ, UCIDES CORDATUS (LINNAEUS, 1763) (CRUSTACEA, BRACHYURA): UMA QUESTÃO ECONÔMICA E DE SAÚDE PÚBLICA NA AMAZÔNIA
}

\author{
Freitas, A.C. ${ }^{1,4,}{ }^{,}$; Fernandes, M.E.B. ${ }^{2}$; Faial, K.C.F. ${ }^{3}$ \& Pinheiro, M.A.A. ${ }^{1,4}$ \\ ${ }^{1}$ Universidade Estadual Paulista (UNESP), Instituto de Biociências (IB), Campus do Litoral Paulista, \\ Laboratório de Biologia da Conservação de Crustáceos (LBC) - CRUSTA. \\ ${ }^{2}$ Universidade Federal do Pará (UFPA), Campus Bragança, Laboratório de Ecologia de Manguezais. \\ ${ }^{3}$ Instituto Evandro Chagas. Laboratório de Toxicologia, Seção de Meio Ambiente. \\ ${ }_{4}^{4}$ Programa de Pós-Graduação em Biodiversidade Aquática, Universidade Estadual Paulista (UNESP). \\ *Autor correspondente: adria.cfreitas@gmail.com
}

\begin{abstract}
Na região Amazônica muitas áreas de manguezal ainda se encontram prístinas. Entretanto, atividades antrópicas de degradação e contaminação, principalmente por metais, começam a alcançar escalas progressivamente preocupantes, afetando este ecossistema e seus recursos. Os caranguejos, como Ucides cordatus, e outros organismos podem absorver uma carga maior destes elementos, que por não serem biodegradáveis se acumulam nos tecidos vivos, chegando ao ser humano através da alimentação. Assim, para avaliar as concentrações de metais nesse crustáceo, foram obtidas amostras em manguezais do Estado do Pará e Maranhão, representados por duas áreas (P, prístina e $A$, antropizada), compostas por três subáreas cada. Foram obtidos 9 caranguejos em cada área, dos quais foram coletadas amostras de quatro tecidos/estruturas de cada animal ( $M$, músculo dos quelípodos; $\mathrm{H}$, hepatopâncreas e $\mathrm{B}$, brânquias), totalizando 108 amostras que foram quantificadas quanto à concentração de cinco metais ( $\mathrm{Cd}, \mathrm{Cu}, \mathrm{Pb}, \mathrm{Cr}$ e Mn) por Espectrometria de Emissão Óptica por Plasma acoplado indutivamente (ICP-OES). As concentração de metal por tecidos/estruturas do caranguejo-uçá foram confrontadas com níveis máximos recomendados para consumo humano pela ANVISA. Em todas as áreas estudadas foram identificadas concentrações acima dos limites máximos recomendados pela agência de saúde em pelo menos uma amostra. Cobre e cromo apresentaram concentrações acima dos valores de referência em $\mathrm{B}$ e $\mathrm{M}$ tanto em P quanto em A (Cu: $\mathrm{B}>\mathrm{M}>30 \mathrm{mg} / \mathrm{kg}$; $\mathrm{Cr}: \mathrm{B}>\mathrm{M}>\mathrm{H}>0,10 \mathrm{mg} / \mathrm{kg}$ ). Cádmio e Chumbo também mostraram certa similaridade, com maior contaminação na musculatura, embora a hierarquia de concentração tenha sido distinta para os demais tecidos $(\mathrm{Cd}: \mathrm{M}>\mathrm{B}>0,5 \mathrm{mg} / \mathrm{kg} ; \mathrm{Pb}: \mathrm{M}>\mathrm{B}>\mathrm{H}>0,5 \mathrm{mg} / \mathrm{kg})$. Apenas manganês apresentou maiores concentrações no hepatopâncreas e menor no músculo $(H>B>M)$, embora a ANVISA não apresente valor de referência para este metal. De modo geral o presente estudo revela que mesmo nos manguezais amazônicos considerados prístinos, as amostras de tecidos/estruturas do caranguejo-uçá apresentaram concentração dos metais avaliados acima do permitido para consumo humano. Tal fato é motivo de grande preocupação, haja vista os riscos à saúde pública pelo consumo da carne e vísceras deste, por serem produtos de grande apelo culinário regional. Especialmente, para os metais não essenciais e de maior periculosidade, como o $\mathrm{Cd}$ e o $\mathrm{Pb}$, o que pode afetar a economia regional que tem neste recurso um importante item comercial.
\end{abstract}

Palavras-chave: Amazônia, caranguejo, contaminantes, manguezal, poluição. 